\title{
Physicochemical, Antibacterial and Antioxidant Properties of Fixed and Essential Oils Extracted from the Peels of Citrus macroptera Fruit
}

\author{
G. MANURANJAN ${ }^{1}$, P. LALDUHSANGA ${ }^{2 *}$, H. LALHLENMAWIA, K. BIBHUTI ${ }^{3}$ AND K. THANZAMI
}

Department of Pharmacy, ${ }^{1}$ Institutional BiotechHub, Department of Pharmacy, Regional Institute of Paramedical and Nursing Sciences, Zemabawk, Aizawl-796 017, ${ }^{2}$ Department of Pharmaceutical Sciences, Assam University, Silchar-788 011, ${ }^{3}$ Department of Pharmaceutical Sciences, Dibrugarh University, Dibrugarh-786 004, India

\section{Manuranjan et al.: Characteristics and Activities of Citrus macroptera oil}

\begin{abstract}
Essential oil was extracted from the fresh and dried peels of Citrus macroptera fruits following hydrodistillation method and fixed oil was isolated using Soxhlet extraction apparatus. The organoleptic characteristics, yield and other physical properties were determined for both the oils. Volatile components of the essential oils were identified using gas chromatography coupled with mass spectrometry. Antibacterial effects were estimated against different pathogenic strains including Klebsiella pneumonia, Pseudomonas aeruginosa, Bacillus subtillis and Escherichia coli. Both preliminary thin layer chromatography method and quantitative 2,2-diphenyl-1-picrylhydrazyl scavenging activity were performed to evaluate the antioxidant potential of the oils and were compared against the standard ascorbic acid. Percent yield of the essential oil from the fresh and dried peels were 0.113 and $0.201 \%$, respectively, while the yield of fixed oil was found to be $3.12 \%$. Gas chromatography coupled with mass spectrometry demonstrated that the essential oils from the dried and fresh peels were composed of about 20 volatile components. The $\mathrm{IC}_{50}$ values determined using the 2,2-diphenyl-1-picrylhydrazyl scavenging activity were 90.56 and $73.010 \mu \mathrm{g} / \mathrm{ml}$, respectively for essential oils extracted from the fresh and dried peels.
\end{abstract}

Key words: Citrus macroptera, essential oil, physicochemical properties, antibacterial, antioxidant

Natural products include those chemical compounds and substances obtained from plants, animals and minerals. They are the backbone on which all the traditional system of healing around the globe depended on. The use of plants and their parts along with oils derived from them as food, medicine and in religious practices was observed in both the eastern and western civilizations ${ }^{[1]}$. In recent years, consumers have also developed more and more interest in natural products due to their perceived safety over synthetic chemical compounds. As a result, products such as essential oils have garnered great popularity in the food, cosmetics and pharmaceutical industries ${ }^{[2]}$.

Essential oils are basically low molecular weight, volatile and complex compounds characterized by strong odour ${ }^{[3]}$. These can be synthesized by different parts of the plant organs and play diverse roles in the plant's defense system as well as reproduction. The International Organization for Standardization has reserved the term 'essential oil' for those products obtained from vegetable raw materials through mechanical or physical process only (pressing or distillation $)^{[2]}$. As such, several essentials oils have also been classified into generally recognized as safe (GRAS) by the United States Food and Drug Administration ${ }^{[1]}$. Essential oils are interesting compounds in that these possess various biological properties, exerting activities on human, animals and other plants. Studies in recent times have shown antibacterial, antifungal, insecticidal and antioxidant properties of essential oils obtained from various plants making them a promising, eco-friendly control system for microorganisms ${ }^{[4-9]}$.

This is an open access article distributed under the terms of the Creative Commons Attribution-NonCommercial-ShareAlike 3.0 License, which allows others to remix, tweak, and build upon the work non-commercially, as long as the author is credited and the new creations are licensed under the identical terms

Accepted 24 November 2018

Revised 23 April 2018

Received 08 March 2017

Indian J Pharm Sci 2019;81(1):82-88 
The genus Citrus belongs to Rutaceae family and the Citrus fruits are the major fruit grown and consumed around the world. The annual global production of Citrus fruits is calculated to be more than 105 million metric tons and India is among the top Citrus fruit producing countries ${ }^{[10]}$. Citrus fruits are mainly processed into juices and they are rich sources of bioactive compounds including essential oils ${ }^{[1]}$. The waste product from the juice processing of these fruits, which include the peels, seeds and pulps representing about $50 \%$ of the raw processed fruit, are a potential source of valuable by-products ${ }^{[12]}$. It was estimated that more than 52 cultivated and wild varieties of Citrus are found in Northeast hilly states of India that includes C. macroptera ${ }^{[13]}$. C. macroptera is locally called as Hatkora in Mizoram and the bitter-sour juice extracted from the fruit is popularly used to treat digestive and other stomach problems. After the juice is extracted, the by-products such as the peels and pulps are usually discarded as wastes and these agro-industrial wastes are potential source for valuable products such as essential oils.

Several authors have reported the composition, antimicrobial, antifungal and antioxidant activities of essential oils, especially from different fruits of the Citrus genus ${ }^{[10,12,14]}$. However, no report has been found on the extraction and characterization of fixed oil from Citrus fruits. The aim of the present work was therefore to extract and compare the components of essential oil extracted from the fresh and dried peels of $C$. macroptera fruits and to isolate the fixed oil from the dried peels. The physicochemical properties of the oils were evaluated and the qualitative analysis of the essential oil was performed through gas chromatography coupled with mass spectrometry (GC-MS). The antibacterial property was evaluated against different pathogenic bacterial strains and the antioxidant activity was determined through 2,2-diphenyl-1-picrylhydrazyl (DPPH) scavenging activity.

\section{MATERIALS AND METHODS}

C. macroptera is a common and well known fruit in Mizoram. The fresh and dried peels of mature fruits were purchased from a local market in Aizawl and washed with distilled water. Both the fresh and dried peels were cut into suitably small pieces before extraction to facilitate the extraction of oils. Essential oil from the fresh and dried peels was extracted using hydro-distillation process in a Clevenger apparatus with slight modification of the hydro-distillation time $^{[13]}$. Exactly $100 \mathrm{~g}$ of the suitably cut peels were taken and placed in the distillation flask followed by hydro-distillation for about $4 \mathrm{~h}$. The condensed steam and vaporized oil were collected in a measuring tube. Being immiscible and lighter than water, the volatile oil separated out as an upper layer, which was collected with the help of a separating funnel. The oils were kept in small vials, labelled and stored at $4-6^{\circ}$ for further use. A Soxhlet apparatus was used for the extraction of fixed oils from the dried peels of C. macroptera. About $400 \mathrm{~g}$ of the dried peels was placed in the thimble and extracted with $n$-hexane as a solvent. The extraction was carried out for $8 \mathrm{~h}$.

Organoleptic properties, specific gravity and colour of the oils were observed under daylight and under ultraviolet radiation at 254 and $366 \mathrm{~nm}$ in a UV chamber. The $\%$ yield was calculated from the total weight of materials used for extraction. The specific gravity of the oils was determined by using a $30 \mathrm{ml}$ specific gravity bottle against water. Brookfield Viscometer (DV-E, Brookfield, USA) was used to determine the viscosity of the oils. The viscosity of the oils was analyzed using spindle no. 63 at $20^{\circ}$ at a shear rate of $4 \mathrm{rpm}$ and the viscosity was recorded in centipoises after the reading was stabilized for $30 \mathrm{~min}$.

About $5 \mathrm{~g}$ of the oil was taken in a flask and to it $50 \mathrm{ml}$ of neutralized alcohol was added, shaken and titrated against $0.1 \mathrm{~N}$ potassium hydroxide $(\mathrm{KOH})$ solution. The total acid number was then calculated using the following Eqn., acid number $=\mathrm{V} \times \mathrm{N} \times 56.1 / \mathrm{W}$, where, $\mathrm{V}$ is the volume of $\mathrm{KOH}$ used, $\mathrm{N}$ is the normality of $\mathrm{KOH}$ and $\mathrm{W}$ is the weight in gram of the sample.

To determine the saponification value, $2 \mathrm{~g}$ of the oil sample was taken and mixed with $25 \mathrm{ml}$ of $0.5 \mathrm{M} \mathrm{KOH}$. After refluxing for $30 \mathrm{~min}$ with periodic shaking to a clear solution, phenolphthalein indicator was added and titrated with $0.5 \mathrm{M} \mathrm{HCl}$. The saponification value was calculated from the following Eqn., saponification value $=(b-a) / m \times 28.05$, where, ' $b$ ' is the volume of $0.5 \mathrm{~N} \mathrm{HCl}$ required by the blank, ' $\mathrm{a}$ ' is the volume of $0.5 \mathrm{~N} \mathrm{HCl}$ required by the sample and ' $\mathrm{m}$ ' is the weight of the oil taken the test.

The iodine value was determined by following the method of Food Safety and Standards Authority of India (FSSAI) ${ }^{[15]}$, taking $0.5 \mathrm{~g}$ of the oil for the analysis. The final solution was titrated with $0.1 \mathrm{~N}$ sodium thiosulphate using starch indicator. The iodine value was then calculated by the following Eqn., iodine value = $[(\mathrm{B}-\mathrm{S}) \times \mathrm{N} \times 12.69] /$ weight of the sample, where, $\mathrm{B}$ is 
the volume $(\mathrm{ml})$ of $0.1 \mathrm{~N}$ sodium thiosulphate required by blank, $\mathrm{S}$ is the volume $(\mathrm{ml})$ of $0.1 \mathrm{~N}$ sodium thiosulphate required by sample and $\mathrm{N}$ is the normality of sodium thiosulphate solution.

The peroxide value was determined by following the method of FSSAI with slight modification ${ }^{[15]}$. About $1.0 \mathrm{~g}$ of the oil sample was taken and to it $1.0 \mathrm{~g}$ of KI and $20 \mathrm{ml}$ of the solvent mixture (glacial acetic acid/ chloroform, $2 / 1 \mathrm{v} / \mathrm{v}$ ) were added to it. The mixture was then boiled for one minute. To a flask containing $20 \mathrm{ml}$ of $5 \% \mathrm{KIO}_{3}$ solution, the hot mixture solution was poured. A few drops of starch solution were added to the mixture and titrated with $0.025 \mathrm{M}$ sodium thiosulphate solution. Peroxide value was expressed as mille-equivalent of peroxide oxygen per $\mathrm{kg}$ sample $(\mathrm{mEq} / \mathrm{kg})$ : peroxide value $=$ titre $\times \mathrm{N} / 100 \times$ weight of the sample, where, $\mathrm{N}$ is the normality of sodium thiosulphate solution.

\section{GC-MS analysis:}

The GC-MS analysis of the essential oil was carried out in a GC-MS spectrometer (ISQ LT Single Quadrupole GC-MS, Thermofisher Scientific). The flow-rate of the Helium carrier gas was maintained at $1 \mathrm{ml} / \mathrm{min}$ and $0.5 \mu \mathrm{l}$ of the samples were injected for analysis. The injector temperature was held at $250^{\circ}$ and the column temperature at $60^{\circ}$ for $5 \mathrm{~min}$, and programmed at $3^{\circ} / \mathrm{min}$ to $180^{\circ}$ and then $20^{\circ} / \mathrm{min}$ to $300^{\circ}$ and held for 20 min with split mode injection (1:25). The column was coupled directly to the quadrupole mass spectrometer in EI mode at $70 \mathrm{eV}$ with a mass range of 5-500 amu at $1 \mathrm{scan} / \mathrm{s}$. The individual compounds were identified by comparing with data available in the NIST Mass Spectral Library Search $2.2 \mathrm{~g}$.

\section{DPPH scavenging activity:}

Prior to performing the DPPH scavenging activity, a preliminary thin-layer chromatography (TLC) bioautography was performed on the essential and fixed oils using $1 \%$ DPPH in methanol as spraying agent. The TLC plate developed a yellow spot on the purple background when the sample exhibit antioxidant activity. The antioxidant activity of the oils and the standard ascorbic acid were then estimated on the basis of the DPPH free radical scavenging ability according to the reported method ${ }^{[16]}$. Ascorbic acid was used as reference standard. The diluted oils $(0.1 \mathrm{ml})$ was mixed and shaken vigorously with $5 \mathrm{ml}$ of DPPH solution $(0.1 \mathrm{mM}$ in methanol). The mixture was then allowed to stand in dark at room temperature $\left(27^{\circ}\right)$ for $20 \mathrm{~min}$. The negative control was prepared as above without any of the essential oil. The reduction in the absorbance of the negative control and the samples was measured at $517 \mathrm{~nm}$ against water as blank.

\section{Antibacterial activity:}

The antibacterial activity was evaluated by disc diffusion method on nutrient agar culture medium. For the preparation of inoculum, pure culture of the microorganism is inoculated in a broth medium and incubated at $37^{\circ}$ for $24 \mathrm{~h}$ and turbidity adjusted to 0.5 McFarland standard. Test organisms used included Pseudomonas aeruginosa (ATCC 10145), Bacillus subtilis (ATCC 11774), Escherichia coli (ATCC 10536) and Klebsiella pneumoniae (ATCC 10031). All the test organisms are purchased from HiMedia Laboratories Private Ltd., Mumbai, India. Discs of antimicrobial agents containing $5 \mu \mathrm{l}$ of oil samples from the peels of $C$. macroptera were placed on the surface of the cultured agar plate and the plates are incubated for 16$18 \mathrm{~h}$ at $37^{\circ}$ and the susceptibility is determined on the basis of zone of inhibition. Ceftriaxone at $30 \mu \mathrm{g} / \mathrm{disc}$ was used as standard.

\section{Statistical analysis:}

Statistical analysis was performed using Microsoft Excel software (MS Office 2007). Data are expressed as mean \pm SD and the results were taken from independent experiments performed in triplicate.

\section{RESULTS AND DISCUSSION}

Different properties of essential oil obtained from the fresh and dried peels of $C$. macroptera as well as the fixed oil from the dried peels were evaluated in the present study. The essential oil obtained was colourless in appearance with a pleasant smell while the fixed oil was yellowish also with a pleasant odour. Table 1 listed the physicochemical characteristics of the fixed and essential oils from C. macroptera. The yield of the fixed oil was $3.12 \pm 0.50 \%$, while the yields of essential oil were $0.201 \pm 0.02$ and $0.113 \pm 0.05 \%$, respectively for the dried and fresh peels of $C$. macroptera. As expected, the specific gravity of the fixed oil (0.982) was found to be higher than the specific gravity for the extracted essential oil (0.692 and 0.671, respectively for fresh and dried peels). The yield of essential oil from fresh peels of $C$. macroptera fruits was comparable to the yield of $0.12 \%$ reported from Bangladesh ${ }^{[17]}$ and lower than $0.53 \%$ reported from Manipur, India ${ }^{[14]}$. 
TABLE 1: PHYSICOCHEMICAL PROPERTIES OF THE FIXED AND ESSENTIAL OILS FROM $C$. MACROPTERA PEELS

\begin{tabular}{lccc}
\hline & $\begin{array}{c}\text { Fixed } \\
\text { oil of } C .\end{array}$ & \multicolumn{2}{c}{$\begin{array}{c}\text { Essential oils of } C . \\
\text { macroptera }\end{array}$} \\
\cline { 3 - 4 } Characteristics & $\begin{array}{c}\text { macropttera } \\
\text { dried peels }\end{array}$ & Fresh peels & Dried peels \\
\hline Colour & $\begin{array}{c}\text { Brownish } \\
\text { yellow } \\
\text { Pleasant }\end{array}$ & Colourless & Colourless \\
Odour & $3.12 \pm 0.50 \%$ & $0.113 \pm 0.05 \%$ & $\begin{array}{c}0.201 \pm 0.02 \\
\%\end{array}$ \\
Yield & & $0.692 \pm 0.02$ & $0.671 \pm 0.01$ \\
Specific gravity & $0.982 \pm 0.01$ & $109 \pm 0.5$ & $117 \pm 0.45$ \\
$\begin{array}{l}\text { Viscosity (cps) } \\
\text { Total acid }\end{array}$ & $113 \pm 0.5$ & & \\
$\begin{array}{l}\text { number } \\
\text { (mg KOH/g oil) }\end{array}$ & $7.34 \pm 0.21$ & & \\
$\begin{array}{l}\text { lodine number } \\
\text { (g/100g oil) }\end{array}$ & $101 \pm 1.50$ & & \\
$\begin{array}{l}\text { Saponification } \\
\text { value } \\
\text { (mg KOH/g) }\end{array}$ & $186.96 \pm 2.10$ & & \\
$\begin{array}{l}\text { Peroxide value } \\
\text { (mEq } \mathrm{O}_{2} / \mathrm{kg} \text { oil) }\end{array}$ & $10.1 \pm 0.5$ & $8.25 \pm 0.32$ & $8.50 \pm 0.21$ \\
\hline
\end{tabular}

The acid number is amount $\mathrm{KOH}$ required to neutralize the free fatty acid present in $1 \mathrm{~g}$ of fats. It indicates the extent of rancidity as free fatty acids are normally formed during decomposition of oil glycerides due to moisture, temperature and/or lypolytic enzyme lipase $^{[15]}$. The acid number in the present study was found to be $7.34 \mathrm{mg} \mathrm{KOH} / \mathrm{g}$ oil for the fixed oil extracted the peels. This acid value is much higher than the acid value reported for the seed oils of different Citrus fruits such as C. limetta (2.18), C. paradise (0.66), C. sinensis (0.55), C. reticulate (1.30) from Pakistan $^{[10]}$, citron seed oil (0.953), orange seed oil (0.673), mandarin seed oil (1.120) and mixed seed oils (0.762) from Egypt $^{[12]}$. The high acid value indicates that the fixed oil obtained from the Citrus peels may be more susceptible to rancidity than the fixed oils obtained from the seeds.

To determine the saponification value, known amount of the fixed oil is refluxed with an excess of alcoholic $\mathrm{KOH}$ solution. It is an index of mean molecular weight of the fatty acids of glycerides comprising a fat, where lower saponification value indicates larger molecular weight of fatty acids in the glycerides and viceversa $^{[15]}$. The fixed oil from the peels of C. macroptera has saponification value of $186.96 \pm 2.10 \mathrm{mg} \mathrm{KOH} / \mathrm{g}$ of the oil. This saponification value is comparable to saponification value reported for the seed oils of C. limetta (180.90), C. paradise (198.85), C. sinensis (189.50), C. reticulate (186.00) from Pakistan ${ }^{[10]}$, citron seed oil (189.5), orange seed oil (190.2), mandarin seed oil (187.2) and mixed seed oils (188.3) from Egypt $^{[12]}$. The Iodine value is the number of grams of iodine absorbed per $100 \mathrm{~g}$ of oil and it is the measure of unsaturation in oil. The iodine value observed for the fixed oil sample of $C$. macroptera in the present study was found to be $101 \pm 1.50$, which is comparable to the iodine value reported for the Citrus seed oils ${ }^{[10,12]}$.

Determination of peroxide value is important in the analysis of fats and oils. It is a measure of the extent to which an oil sample undergoes primary oxidation. The peroxides, especially the organic compounds, are recognized as severely skin irritating, sensitizing and allergic substances and even carcinogenic, depending on the particular molecule. The peroxides values below 20 are acceptable while values below 5 are preferred in cosmetic industries ${ }^{[18]}$. The peroxide values from the present study were found to be $10.1 \pm 0.5$ for fixed oil of C. macroptera and $8.25 \pm 0.32$ and $8.50 \pm 0.21$, respectively for essential oil of fresh and dried peels. The value indicated that both the fixed and essential oils were acceptable in cosmetic industries.

In all around 20 volatile components were identified in GC-MS analysis. The majority of the components present in the oil were monoterpenes, which possessed cyclic structure such as limonene, terpeinene, myrcene, $\alpha$-pinene. Sesquiterpenes such as humulene a nd caryophyllene were also identified in the spectra. Table 2 showed the list of individual compounds identified in the spectra. The compounds identified were comparable to volatile components reported from other Citrus fruits ${ }^{[13,14,17,19]}$.

Methanol extracts of the peels and seeds of differ Citrus fruits were shown to possess antioxidant activity (fig. 1A) ${ }^{[20]}$. Several studies on essential oils extracted from various Citrus fruits and non-Citrus plants also reported their antioxidant potential of such volatile oils ${ }^{[4,6,8,17,21]}$. Fig. 1B shows the radical scavenging effects of different concentrations of fixed and essential oils extracts of C. macroptera. The antioxidant activities of the extracts were compared with that of the standard ascorbic acid, which is a known powerful antioxidant. Both fixed oils and essential oils extracts had radical scavenging effects at all concentrations. However, this effect was not as prominent as the radical scavenging effect of the standard ascorbic acid. The $\mathrm{IC}_{50}$ values of the various extracts were $168.54,90.56$ and $73.01 \mu \mathrm{g} / \mathrm{ml}$, respectively for the fixed oil, essential oils extracted 
TABLE 2: VOLATILE COMPONENTS IDENTIFIED FROM GC-MS SPECTRA OF ESSENTIAL OILS OF C. MACROPTERA PEELS

\begin{tabular}{lc}
\hline & Components \\
\hline Fresh peels & Dried peels \\
\hline a-Pinene & Heptenal \\
a-Myrene & a-Pinene \\
D-Limonene & D-Limonene \\
Y-Terpinen & Terpinene \\
Nonanal & Nonanal \\
Terpineol & 1-cyclopropylpentane \\
Decanal & 3-cyclohexan-1-ol,4- \\
a-Citral & methyl-1-(1- methylethyl) \\
Undecanal & Isothiyol \\
a-Copaene & 2-isopropenyl-5-methyl-4- \\
Caryophyllene & hexanal \\
Humulene & Caryophyllene \\
Cadina-1(10),4-diene & Humulene \\
n-trans-Nerlidol & Hedycaryol \\
a-Cadinol & Nerolidol \\
Globulol & a-Cadinol \\
1-Heptatriacontanol & Pivalate \\
Trans-farnesol & trans-Geranylgeraniol \\
18-octadec-9-enolide & Diisoctyl phthalate \\
Diisooctyl phthalate & Astaxanthin \\
9-octylheptadecane & \\
Astaxanthin & \\
\hline
\end{tabular}
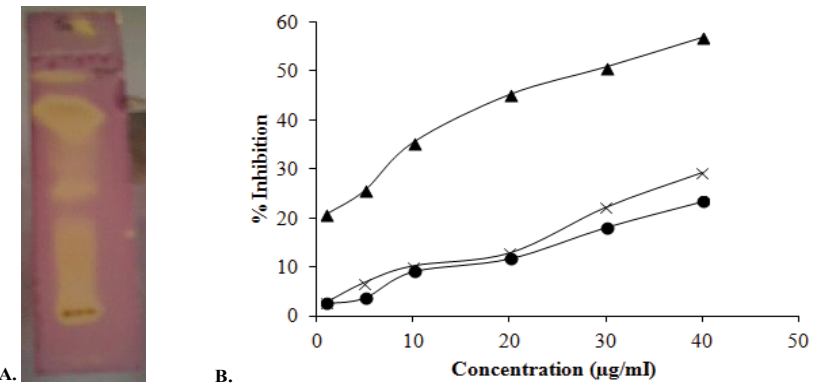

Fig. 1: Antioxidant activity and DPPH scavenging activity of the essential oil

(A) TLC plate showing antioxidant activity (b) DPPH Scavenging activity of the essential oil, $-\times-$ fresh Citrus peels, -๑— dried Citrus peels, $-\Delta-$ ascorbic acid

from fresh and dried peels of C. macroptera. The $\mathrm{IC}_{50}$ of ascorbic acid was calculated to be $29.60 \mu \mathrm{g} / \mathrm{ml}$.

It has been recognized for centuries that essential oils possessed antimicrobial property. Citrus oils have the GRAS status for food and drug applications possessing the inhibitory effects both in direct oil and vapour form against a range of both Gram-positive and Gram-negative bacteria ${ }^{[22]}$. The antifungal activities of various essential oils ${ }^{[7,23]}$ including Citrus fruit peels ${ }^{[13]}$ have also been reported. Therefore, the essential oils of
Citrus plants are promising natural antimicrobial that fulfill the requirements and expectations of both the industry and the consumers. In the present study the antimicrobial activity of both the fixed and essential oils were evaluated against different pathogenic bacterial strains following disc diffusion method (fig. 2). The pathogenic bacterial strains used were E. coli, B. subtilis, P. aeruginosa and $K$. pneumonia. Table 3 showed the zone of inhibition for the samples measured against all the tested organisms. It was observed that the fixed oil obtained from the dried peels of C. macroptera showed antibacterial activity against all the pathogenic strains tested, while the essential oils from both the fresh and dried peels showed little or no inhibitory activity against the test organisms.

The chemical composition, physicochemical properties and bioactivities of the fixed and essential oils obtained from the peels of $C$. macroptera has been evaluated. It was observed that both the fixed and essential oils of the Citrus peel showed typical characteristics and were comparable to the oils reported from other Citrus fruits. Both the oils also possessed antioxidant activity and it was observed that the essential oil exhibit higher antioxidant activity than the fixed oil. When the antibacterial activity was tested against four different pathogenic bacterial strains, the fixed oils showed remarkable antibacterial activity as indicated by the measured zone of inhibitions while the essential oils showed little or no inhibitory activity against the tested

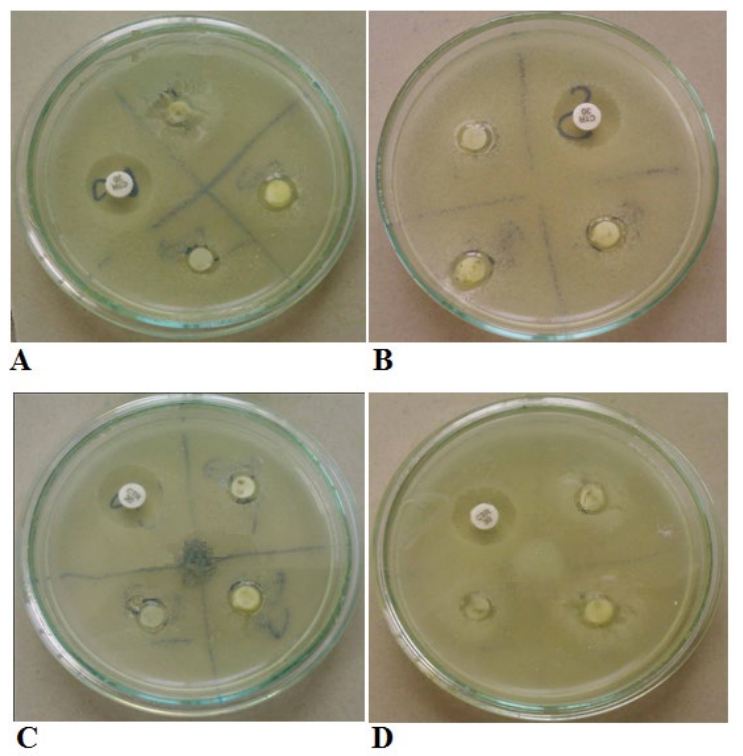

Fig. 2: Zone of inhibition of fixed oil from the peels of $C$. macroptera

A: Klebsiella pneumonia, B: Pseudomonas aeruginosa, C: Bacillus subtillis and D: Escherichia coli, white disc is the standard ceftriaxone $30 \mu \mathrm{g} / \mathrm{disc}$ 
TABLE 3: ZONE OF INHIBITION OF FIXED AND ESSENTIAL OILS FROM C. MACROPTERA PEELS AGAINST DIFFERENT PATHOGENIC BACTERIAL STRAINS

\begin{tabular}{|c|c|c|c|c|}
\hline \multirow[t]{2}{*}{$\begin{array}{l}\text { Test } \\
\text { organisms }\end{array}$} & \multicolumn{3}{|c|}{$\begin{array}{l}\text { Zone of inhibitions }(\mathrm{mm}) \\
\text { against volumes of fixed oil } \\
\text { taken }\end{array}$} & $\begin{array}{l}\text { Zone of } \\
\text { inhibition } \\
(\mathrm{mm}) \\
\text { of standard } \\
\text { ceftrioxone }\end{array}$ \\
\hline & $\mathrm{C} 1(5 \mu \mathrm{l})$ & C2 $(10 \mu \mathrm{l})$ & C3 $(15 \mu \mathrm{l})$ & $30 \mu \mathrm{g} /$ disc \\
\hline E. coli & $9.1 \pm 0.12$ & $8.0 \pm 0.20$ & $9.1 \pm 0.11$ & 18 \\
\hline B.subtillis & $7.0 \pm 0.31$ & $8.2 \pm 0.31$ & $8.2 \pm 0.12$ & 16 \\
\hline P. aeruginosa & $8.2 \pm 0.22$ & $7.4 \pm 0.21$ & $7.1 \pm 0.31$ & 17 \\
\hline K.pneumoniae & $7.1 \pm 0.14$ & $8.1 \pm 0.41$ & $8.0 \pm 0.30$ & 16 \\
\hline
\end{tabular}

organisms. Therefore, waste products of Citrus fruit industry such as the peels of $C$. macroptera, which was discarded after the juices were extracted could be a potential source of valuable by-products in the form of essential oils or fixed oils. Such oils, thus obtained from the waste products of Citrus fruit industry may be incorporated as a component in soap, creams and lotion formula; especially the fixed oil as it has a very pleasant odour as well as antibacterial and antioxidant activity. The essential oil has high potential in perfume industry as has already been used by perfume industry. Since the essential oil component of the fresh and dried peels of Hatkora is more or less the same, the dried peel could serve as a source of essence instead of fresh ones as it is easier to store for a long period of time and transportation cost would also be decreased substantially as the dried peel is much lighter in weight.

\section{Acknowledgement:}

Authors thank the Forensic Science Laboratory, Government of Mizoram for providing facilities for GC-MS analysis.

\section{Conflict of interest:}

Authors reported that there is no conflict of interest.

\section{Financial assistance and scholarship:}

The authors are grateful to the Department of Biotechnology, Government of India for providing financial assistance in the form of Institutional Biotech Hub to the Department of Pharmacy, RIPANS, Aizawl, Mizoram.

\section{REFERENCES}

1. Smith RL, Cohen SM, Doull J, Feron VJ, Goodman JI, Marnett LJ, et al. A procedure for the safety evaluation of natural flavor complexes used as ingredients in food: essential oils. Food ChemToxicol 2005;43:345-63.

2. Turek C, Stintzing FC. Stability of essential oils: A review. Compr Rev Food Sci Food Saf 2013;12:40-53.

3. Bakkali F, Averbeck S, Averbeck D, Idaomar M. Biological effects of essential oils - A review. Food ChemToxicol 2008;46:446-75.

4. Adrar N, Oukil N, Bedjou F. Antioxidant and antibacterial activities of Thymus numidicus and Salvia officinalis essential oils alone or in combination. Ind Crop Prod 2016;88:112-9.

5. Boubaker H, Karim H, El Hamdaoui A, Msanda F, Leach D, Bombarda I, et al. Chemical characterization and antifungal activities of four Thymus species essential oils against postharvest fungal pathogens of Citrus. Ind Crop Prod 2016;86:96-101.

6. Brahmi F, Abdenour A, Bruno M, Silvia P, Alessandra P, Danilo $\mathrm{F}$, et al. Chemical composition and in vitro antimicrobial, insecticidal and antioxidant activities of the essential oils of Mentha pulegium L. and Mentha rotundifolia (L.) Huds growing in Algeria. Ind Crop Prod 2016;88:96-105.

7. Castro JC, Endo EH, De Souza, MR, Zanqueta EB, Polonio JC, Pamphile JA, et al. Bioactivity of essential oils in the control of Alternaria alternata in dragon fruit (Hylocereus undatus Haw.). Ind Crop Prod 2017;97:101-9.

8. Ozcan MM, Erel O, Herken EE. Antioxidant activity, phenolic content, and peroxide value of essential oil and extracts of some medicinal and aromatic plants used as condiments and herbal teas in Turkey. J Med Food 2009;12:198-202.

9. Skocibusic M, Bezic N, Dunkic V. Phytochemical composition and antimicrobial activities of the essential oils from Satureja subspicata Vis. growing in Croatia. Food Chem 2006;96:20-8.

10. Anwar F, Naseer R, Bhanger MI, Ashraf S, Talpur FN, Aladedunye FA. Physico-chemical characteristics of Citrus seeds and seed oils from Pakistan. J Am Oil Chem Soc 2008;85:321-30.

11. Marti N, Mena P, Canovas JA, Micol V, Saura D. Vitamin $\mathrm{C}$ and the role of Citrus juices as functional food. Nat Prod Commun 2009;4:677-700.

12. El-Adawy TA, Rahma EH, El-Bedawy AA, Gafar AM. Properties of some Citrus seeds. Part 3. Evaluation as a new source of protein and oil. Mol Nutr 1999;43:385-91.

13. Chutia M, Deka PB, Pathak MG, Sarma TC, Boruah P. Antifungal activity and chemical composition of Citrus reticulata Blanco essential oil against phytopathogens from North East India. Food Sci Technol 2009;42:777-80.

14. Rana VS, Blazquez MA. Compositions of the volatile oils of Citrus macroptera and C. maxima. Nat Prod Commun 2012;7:1371-2.

15. FSSAI. Manual of methods of analysis of foods (Oils and fats). Food Safety and Standards Authority of India, Ministry of Health and Family Welfare, Government of India, New Delhi, 2015. Available from: https://old.fssai.gov.in/Portals/0/ Pdf/Draft_Manuals/OILS_AND_FAT.pdf.

16. Singh RP, Chidambaramurthy KN, Jayaprakasha GK. Studies on the antioxidant activity of pomegranate (Punica granatum) peel and seed extracts using in vitro models. J Agric Food Chem 2002;50:81-6.

17. Miah MN, Bachar SC, Nahar L, Rahman MS, Rashid MA, Hadiuzzaman S, et al. Composition of the volatiles of Citrus macroptera var. annamensis and evaluation of bioactivity. J Essent Oil Bear P1 2010;13:211-8. 
18. Wabner D. The peroxide value-A new tool for the quality control of essential oils. Int J Aromather 2002;12:142-4.

19. Njoroge SM, Phi NTL, Sawamura M. Chemical composition of peel essential oils of sweet oranges (Citrus sinensis) from Uganda and Rwanda. J Essent Oil Bear Pl 2009;12:26-33.

20. Bocco A, Cuvelier ME, Richard H, Berset C. Antioxidant activity and phenolic composition of Citrus peel and seed extracts. J Agric Food Chem1998;46:2123-9.

21. Said ZBS, Guemghar HH, Makhlouf LB, Rigou P, Remini H,
Adjaoud A, et al. Essential oils composition, antibacterial and antioxidant activities of hydro-distillated extract of Eucalyptus globulus fruits. Ind Crop Prod 2016;89:167-75.

22. Fisher K, Phillips C. Potential antimicrobial uses of essential oils in food: is Citrus the answer? Trends Food Sci Technol 2009;19:156-64.

23. Piras A, Rosa A, Marongiu B, Porcedda S, Falconieri D, Dessi MA, et al. Chemical composition and in vitro bioactivity of the volatile and fixed oils of Nigella sativa L. extracted by supercritical carbon dioxide. Ind Crop Prod 2013;46:317-23. 